\title{
Evaluation of the test-retest reliability of a modified FFQ for assessing food and nutrient intake in Royal Air Force phase-1 recruits
}

\author{
R. Leiper ${ }^{1}$, S. A. Lanham-New ${ }^{2}$, A. Dziubak ${ }^{3}$, D. Whittamore ${ }^{2}$, S. Kilminster ${ }^{3}$ and J. L. Fallowfield ${ }^{3}$ \\ ${ }^{1}$ Regional Medical Centre, RAF Halton, Aylesbury HP22 5PG, Bucks., UK, ${ }^{2}$ University of Surrey, Guildford GU2 7XH, \\ Surrey, UK and ${ }^{3}$ Institute of Naval Medicine, Alverstoke, Gosport PO12 2DL, Hants., UK
}

A FFQ was developed to support investigations into habitual food and nutrient intakes, lifestyle risk factors and incidence of illness and injury during phase-1 recruit training at RAF Halton. The FFQ was modified from a validated questionnaire ${ }^{(1)}$, which has been extensively used $^{(2)}$. The modified FFQ included specific food items available within a UK military training establishment and terminology familiar to young (16-33 years; male and female) recruits. The aim of the present study was to investigate the test-retest reliability of the FFQ, with concomitant validation work $^{(3)}$.

The FFQ was initially piloted in RAF recruits ( $n$ 36), males (31) females (5) who completed the FFQ in a classroom on two separate occasions 1 week apart. Spearman Rank tests were conducted on ranked data in a metric analysis. The 'times per day' items were found to be not reliable but all 'times per week' items were completed by $>90 \%$ of respondents and were reliable $(r 0.5-0.8, P<0.01)$.

Following this first pilot study a modified FFQ was devised in which the 'times per day' items were removed and the 'times per week' Likert scale was reformatted to provide a more intuitive numerical range to improve compliance. This modified FFQ was distributed to a new sample of recruits ( $n$ 33) on two occasions $\left(\mathrm{FFQ}_{1}\right.$ and $\left.\mathrm{FFQ}_{2}\right) 1$ week apart under classroom conditions.

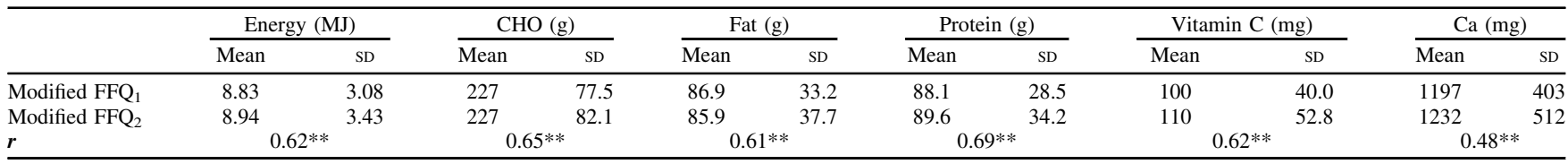

CHO, carbohydrate. $* * P>0.01$ (Spearman Rank test).

Macronutrient intakes determined from the modified FFQ are shown in the Table. The test-retest reliability was consistent with previous studies. Carbohydrate intake represented $45 \%$ total energy intake (fat $38 \%$ total energy, protein $17 \%$ total energy). Recruits reported that the modified FFQ took 22 (SD 8) min to complete and the FFQ instructions and questions were well received. Hence, the utility of the FFQ was suitable for use with recruits in a busy military training establishment.

The authors would like to thank colleagues at RAF Halton, Aylesbury, Bucks., for their support and assistance.

1. Lanham SA \& Bolton-Smith C (1993) Proc Nutr Soc 52, 330A.

2. New SA, Bolton-Smith C, Grubb D et al. (1997) Am J Clin Nutr 65, 1831-1839.

3. Delaney S, Lanham-New SA, Leiper R et al. (2010) Proc Nutr Soc 69, OCE1, E65. 